\title{
Hypolipidemic Effects and Preliminary Mechanism of Chrysanthemum Flavonoids, Its Main Components Luteolin and Luteoloside in Hyperlipidemia Rats
}

\author{
Jihan Sun ${ }^{1,+(\mathbb{C}, \text { Zhaodan Wang }}{ }^{1,2,+}+\mathbb{D}$, Lin Chen ${ }^{1,2}$ and Guiju Sun $1, * \mathbb{C}$ \\ 1 Key Laboratory of Environmental Medicine and Engineering of Ministry \\ of Education, and Department of Nutrition and Food Hygiene, School of Public Health, Southeast University, \\ Nanjing 210009, China; sjhunian@163.com (J.S.); wdeairen07@163.com (Z.W.); friendlin@126.com (L.C.) \\ 2 Technology Research Center of Characteristic Biological Resources in Northeast of Chongqing, \\ College of Biology and Food Engineering, Chongqing Three Gorges University, Chongqing 404130, China \\ * Correspondence: gjsun@seu.edu.cn \\ + These authors contributed equally to this work and should be considered co-first authors.
}

check for updates

Citation: Sun, J.; Wang, Z.; Chen, L.; Sun, G. Hypolipidemic Effects and Preliminary Mechanism of

Chrysanthemum Flavonoids, Its Main Components Luteolin and Luteoloside in Hyperlipidemia Rats. Antioxidants 2021, 10, 1309. https:// doi.org/10.3390/antiox10081309

Academic Editors: María P. Portillo and Raffaella Mastrocola

Received: 26 June 2021

Accepted: 12 August 2021

Published: 20 August 2021

Publisher's Note: MDPI stays neutral with regard to jurisdictional claims in published maps and institutional affiliations.

Copyright: (c) 2021 by the authors. Licensee MDPI, Basel, Switzerland. This article is an open access article distributed under the terms and conditions of the Creative Commons Attribution (CC BY) license (https:// creativecommons.org/licenses/by/ $4.0 /)$.

\begin{abstract}
This study aimed to investigate the key constituents and preliminary mechanism for the hypolipidemic activity of chrysanthemum flavonoids. Hyperlipidemia (HPL) rats were divided into five groups: the model control group (MC); Chrysanthemum flavone intervention group (CF); luteolin intervention group; luteoloside intervention group and simvastatin intervention group. The body weight, organ coefficient, serum lipids, antioxidant activity, and lipid metabolism enzymes were detected. Hematoxylin and eosin (H\&E) staining was used to observe the liver and adipose tissue. Chrysanthemum flavonoids, luteolin, and luteoloside can reduce the weight and levels of total cholesterol (TC), triglycerides (TG), and LDL-C, and increase the level of HDL-C in the blood and reduce liver steatosis. Indicators of liver function (AST, ALT, and ALP) improved. The antioxidant activity (GSH-Px, CAT, SOD) and enzymes associated with lipid catabolism (FA $\beta O$, CYP7A1, and HL) increased, while lipid peroxidation products (MDA) and enzymes associated with lipid synthesis (FAS, HMG-CoA, and DGAT) decreased. Chrysanthemum flavonoids had a better effect on the antioxidant level and lipid metabolism-related enzyme activity. There was no significant difference in the effects of the chrysanthemum flavonoids, luteolin, and Luteoloside on improving blood lipids and hepatic steatosis-mechanisms that may be related to antioxidant levels and regulating enzymes involved in the metabolism of fatty acids, cholesterol, and triglycerides in the liver. However, chrysanthemum flavonoids had a stronger antioxidant and lipid metabolism regulation ability, and the long-term effects may be better.
\end{abstract}

Keywords: chrysanthemum flavonoids; luteolin; luteoloside; hyperlipidemia; hepatic steatosis

\section{Introduction}

Flavonoids, anthocyanins, alkaloids, phenolic acids, and other phytochemicals in flowers have anti-microbial, antioxidant, anti-inflammatory, anticancer, anti-obesity, and neuroprotective effects, which provide the theoretical basis for their health benefits [1]. In the latest Chinese pharmacopeia (2015 edition), among 521 Chinese herbal medicines, 28 were flower-derived [2]. Chrysanthemum (Chrysanthemum morifolium Ramat.), the most representative flower-derived dietary herbal medicine, has been used for more than 2000 years in China and has been recorded in the Chinese pharmacopeia since 1967 [3]. Its flower head, named Juhua in Chinese, is widely used in traditional Chinese medicine, as a food supplement, and in herb tea [4].

Flavonoids are the major compounds in chrysanthemum and are responsible for their colorful appearance. Most of them are luteolin, apigenin, acacetin, diosmetin, or their glycosidic derivatives [5,6]. Many analytical technologies have been applied for quality 
control of Chrysanthemum. TLC and HPLC/UPLC are essential methods for quality control of herb medicines or food supplements. Six compounds, including luteolin, chlorogenic acid, 3,5-di-O-caffeoylquinic acid, luteolin 7-O- $\beta$-d-glucopyranoside, kaempferol, and acacetin were identified by reverse-phase thin layer chromatography (RP-TLC) [7], and the contents of chlorogenic acid, 3,5-di-O-caffeoylquinic acid, and luteolin 7-O- $\beta$-dglucopyranoside are no less than $0.20 \%, 0.70 \%$, and $0.08 \%$, using HPLC combined with a UV detector for determination [8]. However, the weakness of TLC and HPLC/UPLC lies in their relatively low sensitivity and suitability for compounds with large quantities; LC-MS and GC-MS were applied for the analysis of minor compounds. Our previous studies have shown that chrysanthemum has a very high content of total flavonoids and total steroids in 12 edible flowers [9], and showed good antioxidant effects in vivo and in vitro [10]. Chrysanthemum is a popular traditional Chinese medicine used for cardiovascular diseases, especially hyperlipidemia and hypertension. Accordingly, the hypolipidemic and antihypertensive activities of its extracts by different solvents are active in varying degrees [11-13]. The hypolipidemic effect of chrysanthemum total flavonoids on hyperlipidemia in rats has been proven [14]. However, the pure compounds were not investigated to explain which constituents were the key attributes to the clinical therapy of hyperlipidemia. We determined the total flavonoids in chrysanthemum and found that the contents of luteolin and luteoloside in different varieties of chrysanthemum were very high, and there was a certain correlation between the antioxidant activity and the content of total flavonoids [15]. The flavonoids of chrysanthemum were isolated and purified by AB- 8 macroporous adsorption resin and identified by LC-MS/MS. The flavonoids contained luteolin-7-glucoside, luteolin, apigenin, and apigenin-7-glucoside [16]. We also optimized the extraction method of chrysanthemum flavonoids [17] and established a high-performance liquid chromatography (HPLC) method for the determination of luteolin-7-O-glucoside in chrysanthemum [18].

In this study, we hypothesized that luteolin and luteoloside are the main components of chrysanthemum flavonoids that play a role in lowering blood lipids, and their mechanism of action is related to antioxidant activity. We used hyperlipidemia rats to investigate the lipid metabolism improving effects of chrysanthemum flavonoids and its main components, luteolin, and luteoloside, by focusing on the serum lipids, liver pathology, antioxidant activity, and enzymes related to lipid metabolism. The findings will help understand the key constituents and preliminary mechanisms for the hypolipidemic activity of chrysanthemum flavonoids.

\section{Materials and Methods}

\subsection{Materials}

The pure products of chrysanthemum flavonoids, luteolin, luteoloside, and simvastatin were all purchased from the Nanjing Zelang Pharmaceutical Company. Sodium carboxymethyl cellulose (CMC) solution $(0.5 \%)$ was used to prepare gastric gavage fluid, and the concentrations of the chrysanthemum flavonoids, luteolin, luteoloside and simvastatin were $10 \mathrm{mg} / \mathrm{mL}, 5 \mathrm{mg} / \mathrm{mL}, 2.5 \mathrm{mg} / \mathrm{mL}$, and $1 \mathrm{mg} / \mathrm{mL}$, respectively, which was equivalent to the intervention dose chrysanthemum flavonoids of $100 \mathrm{mg} / \mathrm{kg}$, luteolin $50 \mathrm{mg} / \mathrm{kg}$, luteoloside $25 \mathrm{mg} / \mathrm{kg}$, and simvastatin $10 \mathrm{mg} / \mathrm{kg}$.

\subsection{Hyperlipidemia Rats Model and Experimental Design}

Sixty SPF male Sprague-Dawley rats (200 \pm 9 g) were purchased from Nanjing Medical University, and the license was SYXK (SU) 2016-0014. The rats were housed five per cage in a room with a $12 \mathrm{~h}$ diurnal cycle and an ambient temperature of $22 \sim 24{ }^{\circ} \mathrm{C}$. The animal ethics approval was 2015ZDSYLL004.0.

All animals were fed adaptively for one week by a D12450B diet and then randomly divided into a normal control group $(\mathrm{NC}, \mathrm{n}=10)$ fed by a D12450B diet, and a model group $(\mathrm{n}=50)$ fed by a D12492 high-fat diet. The diet ingredients are shown in Table 1. After 4 weeks of modeling, the serum TG and TC in the model group were significantly 
higher than those in the normal control group $(p<0.05)$, and the modeling was judged to be successful.

Table 1. Composition of the D12450B and D12492 diets (total calories were $4057 \mathrm{Kcal}$ ).

\begin{tabular}{ccc}
\hline Component & $\mathbf{1 0} \mathbf{\%}$ kcal-D12450B(g) & $\mathbf{6 0} \mathbf{\%}$ kcal-D12492(g) \\
\hline Casein, 30Mesh & 200 & 200 \\
cystine & 3 & 3 \\
Corn starch & 315 & 0 \\
maltodextrin & 35 & 125 \\
sucrose & 350 & 68.8 \\
Cellulose, BW200 & 50 & 50 \\
Soybean oil & 25 & 25 \\
lard & 20 & 245 \\
The composite mineral s10026 & 10 & 10 \\
dicalcium phosphate & 13 & 13 \\
calcium carbonate & 5.5 & 5.5 \\
potassium citrate, $1 \mathrm{H} \mathrm{H}_{2} \mathrm{O}$ & 16.5 & 16.5 \\
Multi-VitaminsV10001 & 10 & 10 \\
Choline tartrate & 2 & 2 \\
FD\&C yellow \#5 & 0.05 & 0.05 \\
\hline
\end{tabular}

According to the serum TG and TC, fifty male hyperlipidemia rats were randomly divided into five groups, including the model control group (MC); chrysanthemum flavone intervention group (CF); luteolin intervention group; luteoloside intervention group, and simvastatin intervention group. The different intervention solutions (diluted with $0.5 \%$ $\mathrm{CMC}$ solution) were intragastrically administered to four intervention groups every day for 6 weeks at $10 \mathrm{~mL} / \mathrm{kg}$, and $0.5 \% \mathrm{CMC}$ solution was given to the normal control group and the model control group. Intervention doses for each group are shown in Table 2. The body weight was weighed every Monday morning.

Table 2. Experimental groups and treatment doses.

\begin{tabular}{ccc}
\hline Group & Dose of Gavage Administration & Diet \\
\hline Normal control group & $0.05 \mathrm{~g} / \mathrm{kg} \cdot \mathrm{bw} / \mathrm{d}$ 0.5\% CMC \\
solution & D12450B \\
Model control group & $0.05 \mathrm{~g} / \mathrm{kg} \cdot \mathrm{bw} / \mathrm{d} 0.5 \% \mathrm{CMC}$ & $\mathrm{D} 12492$ \\
solution & $100 \mathrm{mg} / \mathrm{kg} \cdot \mathrm{bw} / \mathrm{d}$ & $\mathrm{D} 12492$ \\
Chrysanthemum Flavonoids & Chrysanthemum Flavonoids [19] & $\mathrm{D} 12492$ \\
Luteolin intervention group & $50 \mathrm{mg} / \mathrm{kg} \cdot \mathrm{bw} / \mathrm{d}$ Luteolin [20] & $\mathrm{D} 12492$ \\
Luteoloside intervention group & $25 \mathrm{mg} / \mathrm{kg} \cdot \mathrm{bw} / \mathrm{d}$ Luteoloside [21] \\
Simvastatin intervention group & $10 \mathrm{mg} / \mathrm{kg} \cdot \mathrm{bw} / \mathrm{d}$ Simvastatin [22] & D12492 \\
\hline
\end{tabular}

\subsection{Collection of Blood and Tissue Samples}

At the end of the intervention, all rats were anesthetized with pentobarbital sodium and cervical decapitated after fasting for $12 \mathrm{~h}$. Blood was collected from the femoral artery and centrifuged at $3000 \mathrm{rpm}$ for $15 \mathrm{~min}$. The serum was stored at $-20^{\circ} \mathrm{C}$. Liver and total visceral fat (peri-testicular, peri-renal, mesenteric, and retroperitoneal fat) were rapidly separated and weighed. Feces and liver were frozen in liquid nitrogen and stored at $-80^{\circ} \mathrm{C}$.

\subsection{Biochemical Assays}

TC, TG, high-density lipoprotein cholesterol (HDL-C), low-density lipoprotein cholesterol (LDL-C), apolipoprotein-A (Apo-A), apolipoprotein-B (Apo-B), aspartate aminotransferase (AST), alkaline phosphatase (ALP), and alanine aminotransferase (ALT) were determined by an automatic biochemical analyzer (Bechman coulter, America). The liver tissue was thoroughly mixed with normal saline at 1:9 (mg: $\mu \mathrm{L})$, centrifuged at $3000 \mathrm{rpm}$ for 
$10 \mathrm{~min}$ and the supernatant $10 \%$ liver homogenate was prepared. Glutathione peroxidase (GSH-Px), malondialdehyde (MDA), superoxide dismutase (SOD), and catalase (CAT) were respectively measured by colorimetry, TBA, hydroxylamine, and visible spectrophotometry methods. Liver homogenate $(1 \mathrm{~mL}=0.1 \mathrm{~g})$ was prepared by mixing $10 \mathrm{mg}$ of tissue with 100 microliters of PBS and then fatty acid synthase (FAS), cholesterol 7-alpha-hydroxylase (CYP7A), diacylglycerol acyltransferase (DGAT), fatty acid $\beta$ oxidase (FA $\beta O)$, 3-hydroxy3-methylglutaryl-coenzyme A (HMG-CoA), and hepatic lipase (HL) were analyzed by commercial ELISA assay kits (Nanjing Jiancheng Bioengineering Institute, China) using an ELISA analyzer (RT-6100, Rayto, China).

Calculation of other evaluation parameters: The ratio of body fat $=$ total fat weight $(\mathrm{g}) / \mathrm{body}$ weight $(\mathrm{g}) \times 100 \%$; liver index $=$ wet liver weight $(\mathrm{g}) /$ body weight $(\mathrm{g}) \times 100 \%$.

\subsection{Pathological Observation of Liver and Peri-Testicular Fat}

The liver and peri-testicular fat were fixed with $10 \%$ neutral formaldehyde for $48 \mathrm{~h}$. Paraffin sections were prepared and stained with hematoxylin and eosin (H\&E). The degree of hepatic steatosis was quantitatively analyzed by Image-pro Plus 6.0 ( 0 point was normal, 1 point was less than $5 \%, 2$ points was $5-30 \%, 3$ points was $30-50 \%, 4$ points was $50-75 \%$, and 5 points was greater than $75 \%)$. The number of adipocytes per unit area $\left(25 \mathrm{~mm}^{2} / 200 \times\right)$ was measured with a "micrometer for microscope".

\subsection{Statistical Analysis}

Data were presented as the mean $\pm \operatorname{SEM}(\bar{x} \pm \mathrm{s})$. The independent sample $t$-test was used between the two groups, and differences between three or more groups were analyzed by one-way ANOVA and then multiple comparison tests (SPSS 21 software). A $p<0.05$ was considered statistically significant.

\section{Results}

\subsection{Establishment of Animal Models}

As shown in Table 3, compared with the NC group, serum TC, TG, and LDL-C in the model group were significantly increased and HDL-C was significantly decreased $(p<0.05)$, indicating that the hyperlipidemia SD rat model was established successfully.

Table 3. Blood lipids in the normal control and model group rats after 4 weeks of modeling.

\begin{tabular}{ccccc}
\hline Group & TC(mmol/L) & TG(mmol/L) & $\begin{array}{c}\text { HDL- } \\
\text { C(mmol/L) }\end{array}$ & $\begin{array}{c}\text { LDL- } \\
\text { C(mmol/L) }\end{array}$ \\
\hline $\begin{array}{c}\text { Normal control group } \\
\text { Model group }\end{array}$ & $2.05 \pm 0.35$ & $0.51 \pm 0.14$ & $0.42 \pm 0.14$ & $0.66 \pm 0.17$ \\
\hline * Compan & $2.42 \pm 0.36^{*}$ & $0.63 \pm 0.16^{*}$ & $0.33 \pm 0.11^{*}$ & $0.82 \pm 0.21^{*}$ \\
\hline
\end{tabular}

${ }^{*}$ Compared with the normal control group, $p<0.05$.

\subsection{Effects of Different Intervention on Body Weight of Hyperlipidemia Rats}

The body weight in each group increased gradually (Figure 1). From the 4th week, the weight growth rate of the model control group was significantly faster than that of the other four intervention groups.

\subsection{Liver Index, Total Fat and Body Fat Ratio}

The ratios of the liver and total fat to body weight were expressed as the relative weight per $100 \mathrm{~g}$ body weight (Table 4). The liver index and body fat ratio of the NC group were significantly lower than the MC group $(p<0.05)$. After 6 weeks, the $C F$, luteolin, and simvastatin groups were significantly lower than the MC group $(p<0.05)$. There were no significant differences between the three intervention groups and the simvastatin group. 


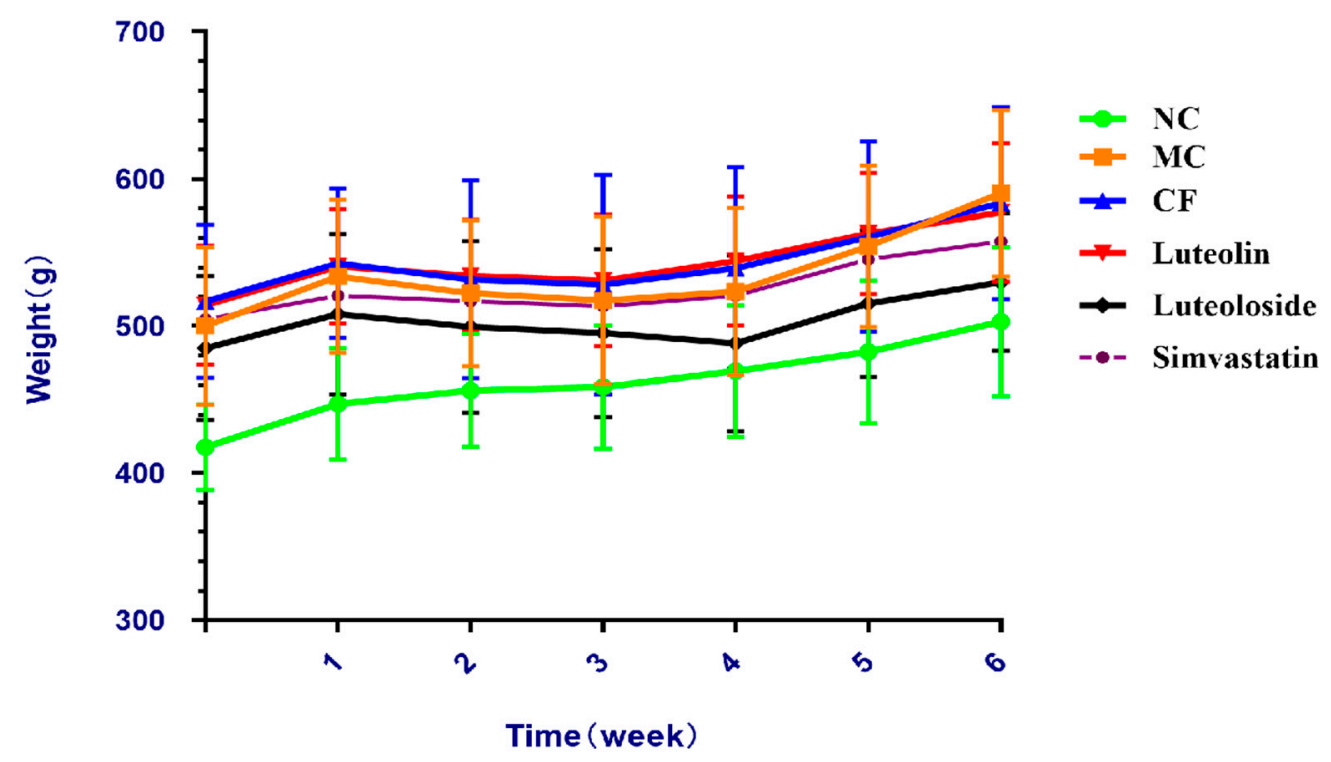

Figure 1. Body weight of different groups during intervention.

Table 4. Body weight, liver weight, liver index, total fat, and body fat ratio in each group.

\begin{tabular}{cccccc}
\hline Group & Liver Weight (g) & Total Fat (g) & Body Weight (g) & Liver Index (\%) & Body Fat Ratio (\%) \\
\hline NC & $10.87 \pm 1.47^{\mathrm{a}}$ & $23.51 \pm 7.95$ & $503.00 \pm 50.47^{\mathrm{a}}$ & $2.13 \pm 0.21$ & $4.88 \pm 1.54$ \\
MC & $14.48 \pm 1.21^{\mathrm{a}}$ & $43.06 \pm 11.64^{\mathrm{a}}$ & $596.67 \pm 56.26^{\mathrm{a}}$ & $2.64 \pm 0.16^{\mathrm{a}}$ & $7.40 \pm 1.28^{\mathrm{a}}$ \\
CF & $12.57 \pm 1.27^{\mathrm{b}}$ & $33.53 \pm 10.70^{\mathrm{b}}$ & $583.50 \pm 65.43^{\mathrm{a}}$ & $2.15 \pm 0.26^{\mathrm{b}}$ & $5.82 \pm 0.83^{\mathrm{b}}$ \\
Luteolin & $12.20 \pm 1.15^{\mathrm{b}}$ & $32.32 \pm 8.97^{\mathrm{b}}$ & $577.30 \pm 46.86^{\mathrm{a}}$ & $2.12 \pm 0.18^{\mathrm{b}}$ & $5.62 \pm 1.41^{\mathrm{b}}$ \\
Luteoloside & $11.51 \pm 0.94^{\mathrm{b}}$ & $28.40 \pm 6.95^{\mathrm{b}}$ & $529.80 \pm 46.76^{\mathrm{b}}$ & $2.17 \pm 0.06^{\mathrm{b}}$ & $5.36 \pm 1.24^{\mathrm{b}}$ \\
Simvastatin & $11.36 \pm 0.75^{\mathrm{b}}$ & $29.10 \pm 6.59^{\mathrm{b}}$ & $540.83 \pm 30.63^{\mathrm{b}}$ & $2.10 \pm 0.15^{\mathrm{b}}$ & $5.11 \pm 0.98^{\mathrm{b}}$ \\
\hline
\end{tabular}

${ }^{\mathrm{a}}$ Compared with NC, $p>0.05$; $^{\mathrm{b}}$ Compared with $\mathrm{MC}, p<0.05$.

\subsection{Serum Lipid Concentrations of Each Groups}

As shown in Table 5, the TG, TC, and LDL-C in serum in the MC group were significantly higher than that in the NC group, while the HDL-C was significantly lower $(p<0.05)$. After the intervention of $\mathrm{CF}$, luteolin, luteoloside, and simvastatin, the level of TG, TC, and LDL-C in serum decreased significantly $(p<0.05)$, but there was no significant difference in HDL-C. Compared with the CF group, the simvastatin group was significantly lower $(p<0.05)$. There were no significant differences between the three intervention groups.

Table 5. The serum levels of TG, TC, HDL-C, and LDL-C in serum in each group.

\begin{tabular}{ccccc}
\hline Group & TC(mmol/L) & TG(mmol/L) & LDL-C(mmol/L) & $\begin{array}{c}\text { HDL- } \\
\text { C(mmol/L) }\end{array}$ \\
\hline NC & $1.95 \pm 0.33$ & $0.68 \pm 0.12^{\mathrm{a}}$ & $0.42 \pm 0.09$ & $1.02 \pm 0.29$ \\
MC & $2.74 \pm 0.63^{\mathrm{a}}$ & $1.42 \pm 0.53^{\mathrm{a}}$ & $0.68 \pm 0.15^{\mathrm{a}}$ & $0.82 \pm 0.12^{\mathrm{a}}$ \\
CF & $2.23 \pm 0.32^{\mathrm{b}}$ & $0.69 \pm 0.21^{\mathrm{b}}$ & $0.50 \pm 0.08^{\mathrm{b}}$ & $0.84 \pm 0.19$ \\
Luteolin & $2.05 \pm 0.24^{\mathrm{b}}$ & $0.52 \pm 0.13^{\mathrm{b}}$ & $0.45 \pm 0.04^{\mathrm{b}}$ & $0.87 \pm 0.15$ \\
Luteoloside & $2.05 \pm 0.39^{\mathrm{b}}$ & $0.48 \pm 0.06^{\mathrm{b}}$ & $0.43 \pm 0.12^{\mathrm{b}}$ & $0.85 \pm 0.20$ \\
Simvastatin & $2.04 \pm 0.28^{\mathrm{b}}$ & $0.57 \pm 0.10^{\mathrm{b}}$ & $0.39 \pm 0.04^{\mathrm{b}, \mathrm{c}}$ & $0.87 \pm 0.11$ \\
\hline
\end{tabular}

a Compared with NC, $p<0.05 ;{ }^{\mathrm{b}}$ Compared with $\mathrm{MC}, p<0.05 ;{ }^{\mathrm{c}}$ Compared with $\mathrm{CF}, p<0.05$.

As shown in Table 6, the Apo-A1 in the MC group was significantly higher than that in the NC group. Apo-B in the MC group was higher than that in the NC group, but the difference was not statistically significant. Compared with the MC group, Apo-A1 in the $\mathrm{CF}$ group and luteoloside were significantly higher, and Apo-B in the $\mathrm{CF}$ group was significantly lower $(p<0.05)$. Compared with the simvastatin group, Apo-B in the $C F$ group was significantly lower $(p<0.05)$. Compared with the CF group, Apo-B in luteoloside and the simvastatin group were significantly higher $(p<0.05)$. 
Table 6. Changes of Apo-A1, Apo-B, and Apo-B/Apo-A1 in SD rats of each group.

\begin{tabular}{cccc}
\hline Group & Apo-A1(ng/mL) & Apo-B(ng/mL) & Apo-B/Apo-A1 \\
\hline NC & $20.20 \pm 2.80$ & $59.64 \pm 3.04$ & $3.03 \pm 0.35$ \\
MC & $15.52 \pm 3.01^{\mathrm{a}}$ & $64.00 \pm 9.28$ & $4.00 \pm 1.23$ \\
CF & $20.32 \pm 3.72^{\mathrm{b}}$ & $50.32 \pm 9.55^{\mathrm{b}}$ & $2.93 \pm 0.91$ \\
Luteolin & $18.17 \pm 0.95$ & $60.37 \pm 8.23$ & $2.50 \pm 0.28$ \\
Luteoloside & $20.54 \pm 6.93^{\mathrm{b}}$ & $62.87 \pm 4.86^{\mathrm{c}}$ & $3.50 \pm 1.63$ \\
Simvastatin & $18.88 \pm 3.92^{\mathrm{b}}$ & $61.73 \pm 4.96^{\mathrm{c}}$ & $3.44 \pm 0.68$ \\
\hline
\end{tabular}

a Compared with NC, $p<0.05 ;{ }^{\mathrm{b}}$ Compared with MC, $p<0.05 ;{ }^{\mathrm{c}}$ Compared with $\mathrm{CF}, p<0.05$.

\subsection{Pathomorphological Features of Each Groups}

The pathomorphological features of liver and peri-testicular fat tissues were observed (Figure 2).
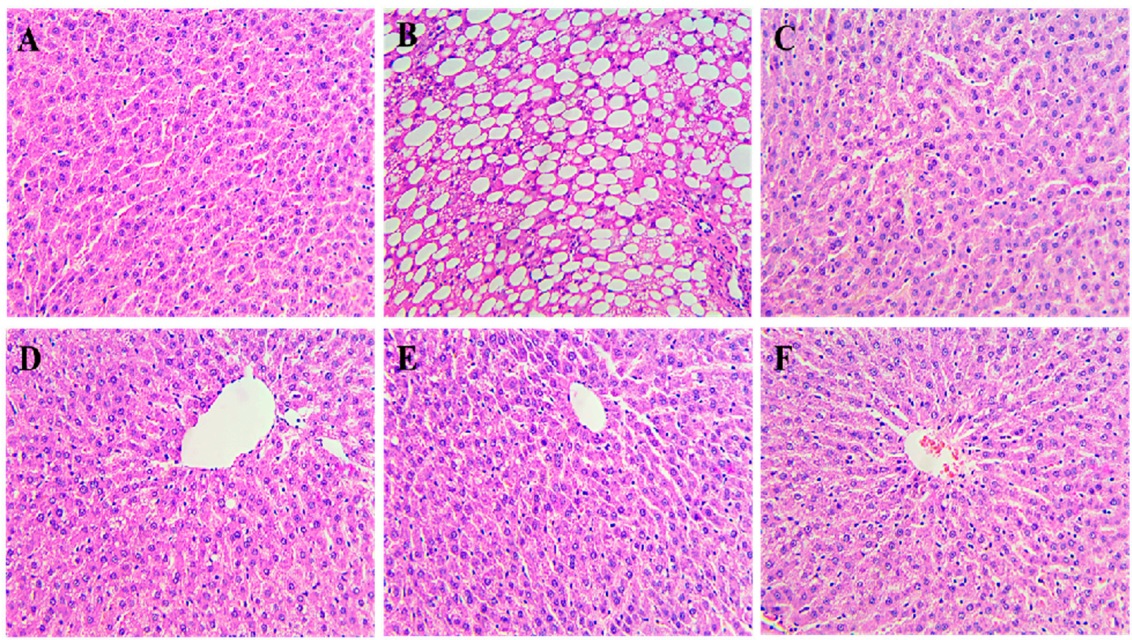

(a)
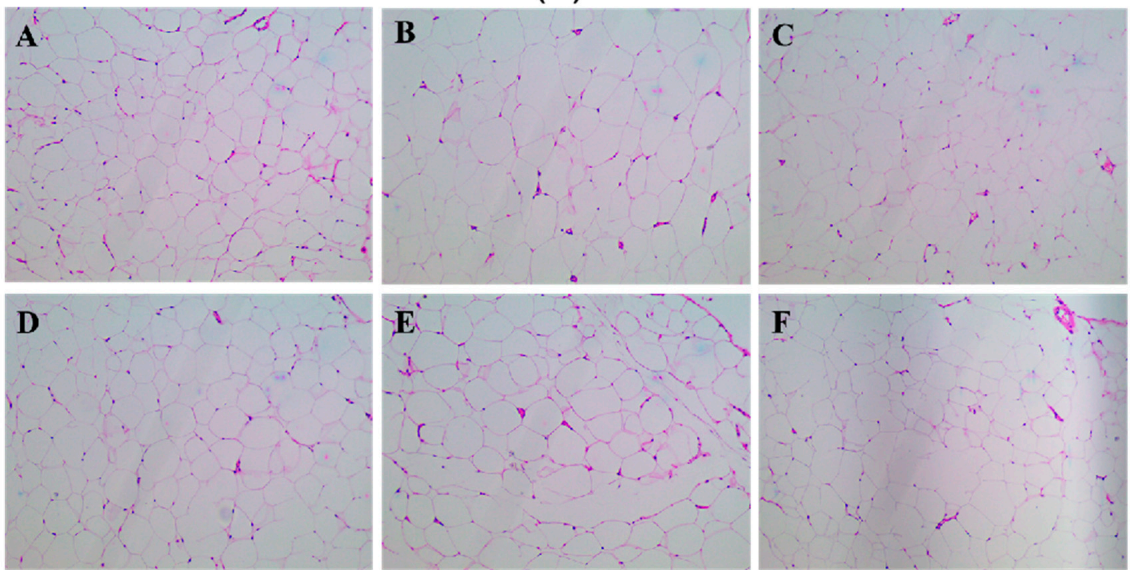

(b)

Figure 2. Pathological observation of liver (a) and peri-testicular fat (b). (A): the normal control group(NC); (B): the model control group(MC); (C): Chrysanthemum flavone intervention group $(\mathrm{CF})$; (D): Luteolin intervention group; (F): Luteoloside intervention group; (E): Simvastatin intervention group.

Liver(a): The liver tissue of the NC group (A) was clear, and significant lipid droplets were not clearly observed. The hepatic sinuses of the MC group (B) disappeared and a large number of lipid droplets appeared. As shown in Figure 3, compared with the NC group, the degree of hepatic steatosis in the MC group was significantly increased $(p<0.05)$. After the intervention of chrysanthemum flavonoids (C), luteolin (D), Luteoloside (E), and sim- 
vastatin (F), the structure of hepatic sinuses were clear, and the lipid droplets were reduced. Compared with the MC group, the degree of lipidosis was significantly reduced $(p<0.05)$. The differences between the four intervention groups were not statistically significant.

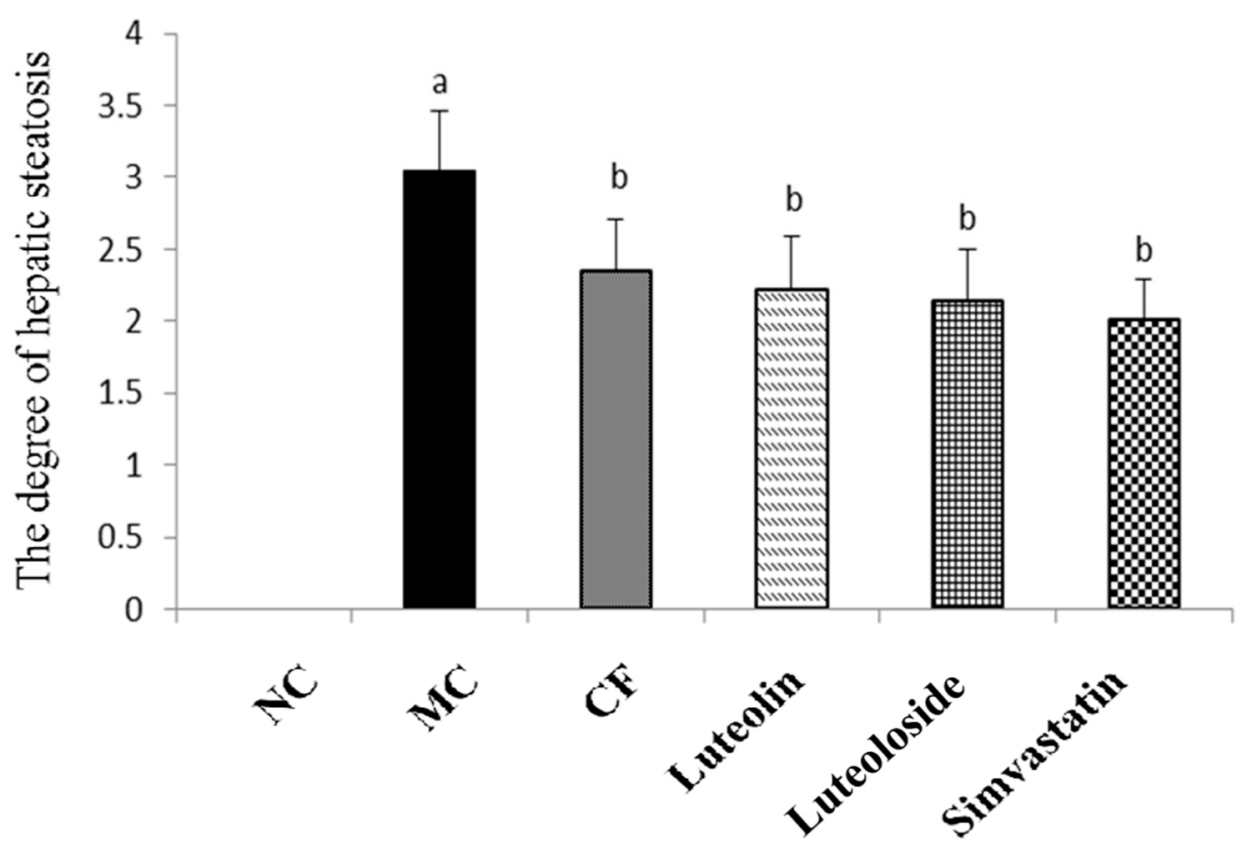

Figure 3. The steatosis score of liver in SD rats of each group. ${ }^{a}$ Compared with $\mathrm{NC}, p<0.05 ; \mathrm{b}$ Compared with MC, $p<0.05$.

Adipocytes(b): The adipocytes tissue of the NC group (A) had a clear outline and uniform size; compared with NC, adipocytes in the MC group (B) were uneven in size, with a general increase in the cross-sectional area and a tendency of fusion at some cell junctions. As shown in Table 7, compared with the NC group, the number of adipocytes in the MC group decreased significantly per $25 \mathrm{~mm}^{2}(p<0.05)$. After the intervention of chrysanthemum flavonoids (C), luteolin (D), luteoloside (E), and simvastatin (F), the cross-sectional area of the adipocytes decreased, and the morphology of adipocytes became gradually uniform. Compared with the MC group, the number of adipocytes was significantly reduced $(p<0.05)$. There was no statistical difference in the number of adipocytes among the intervention groups.

Table 7. Changes in the number of adipocytes in each group.

\begin{tabular}{cc}
\hline Group & Number of Adipocytes (per $\left.\mathbf{2 5} \mathbf{~ m m}^{\mathbf{2}} \mathbf{2 0 0 \times}\right)$ \\
\hline NC & $16.8 \pm 1.3$ \\
MC & $12.5 \pm 1.7^{\mathrm{a}}$ \\
CF & $16.2 \pm 2.1^{\mathrm{b}}$ \\
Luteolin & $15.9 \pm 2.5^{\mathrm{b}}$ \\
Luteoloside & $15.1 \pm 2.4^{\mathrm{b}}$ \\
Simvastatin & $15.6 \pm 1.9^{\mathrm{b}}$ \\
\hline
\end{tabular}

a Compared with NC, $p<0.05 ;^{\mathrm{b}}$ Compared with $\mathrm{MC}, p<0.05$.

\subsection{Indicators of Liver Function in Serum}

As shown in Table 8, compared with the NC group, the level of AST, ALT, and ALP in serum in the MC group increased significantly $(p<0.05)$. Compared with the MC group, AST, ALT, and ALP in the three intervention groups and the simvastatin group decreased significantly $(p<0.05)$, except AST in the luteolin group. There were no significant differences between the three intervention groups. 
Table 8. Changes of AST, ALT, and ALP in the serum of each group.

\begin{tabular}{cccc}
\hline Group & AST(IU/L) & ALP(IU/L) & ALT(IU/L) \\
\hline NC & $135.29 \pm 16.94$ & $106.11 \pm 17.81$ & $39.78 \pm 8.76$ \\
MC & $161.50 \pm 33.20^{\mathrm{a}}$ & $203.40 \pm 66.89^{\mathrm{a}}$ & $57.10 \pm 14.10^{\mathrm{a}}$ \\
CF & $125.50 \pm 28.75^{\mathrm{b}}$ & $132.60 \pm 48.87^{\mathrm{b}}$ & $49.87 \pm 10.06^{\mathrm{b}}$ \\
Luteolin & $142.22 \pm 19.72^{\mathrm{b}}$ & $118.40 \pm 15.35^{\mathrm{b}}$ & $45.30 \pm 10.43^{\mathrm{b}}$ \\
Luteoloside & $126.25 \pm 15.28^{\mathrm{b}}$ & $105.40 \pm 19.55^{\mathrm{b}}$ & $39.60 \pm 7.44^{\mathrm{b}}$ \\
Simvastatin & $126.00 \pm 22.42^{\mathrm{b}}$ & $120.00 \pm 33.88^{\mathrm{b}}$ & $41.57 \pm 5.44^{\mathrm{b}}$ \\
\hline
\end{tabular}

${ }^{\mathrm{a}}$ Compared with NC, $p<0.05 ;^{\mathrm{b}}$ Compared with MC, $p<0.05$.

\subsection{Antioxidant Levels in Livers}

As shown in Table 9, compared with the NC group, the antioxidant level in liver tissue in the MC group decreased. In particular, CAT in liver tissue decreased and MDA increased $(p<0.05)$. Compared with the MC group, chrysanthemum flavonoids significantly improved the levels of GSH-Px and CAT ( $p<0.05)$. Luteolin, luteoloside, and simvastatin all significantly decreased CAT and increased MDA $(p<0.05)$. Compared with the CF group, liver GSH-Px in the luteolin, luteoloside, and simvastatin groups were significantly decreased $(p<0.05)$, and there was no significant difference in other indicators among the three intervention groups.

Table 9. GSH-Px, CAT, SOD, and MDA in the livers of each group.

\begin{tabular}{ccccc}
\hline Group & GSH-Px(U/mgprot) & CAT(U/mgprot) & SOD(U/mgprot) & MDA(nmol/mL) \\
\hline NC & $913.98 \pm 275.71$ & $51.81 \pm 14.33$ & $199.70 \pm 35.54$ & $1.07 \pm 0.18$ \\
MC & $665.14 \pm 313.03$ & $33.31 \pm 5.08^{\mathrm{a}}$ & $186.56 \pm 42.59$ & $1.48 \pm 0.38^{\mathrm{a}}$ \\
CF & $1553.13 \pm 306.73^{\mathrm{a}} \mathrm{b}^{\mathrm{b}}$ & $52.65 \pm 11.85^{\mathrm{b}}$ & $229.00 \pm 47.41$ & $1.26 \pm 0.32$ \\
Luteolin & $980.99 \pm 380.80^{\mathrm{c}}$ & $51.46 \pm 14.12^{\mathrm{b}}$ & $202.26 \pm 57.03$ & $1.1 \pm 0.34^{\mathrm{b}}$ \\
Luteoloside & $975.52 \pm 212.04^{\mathrm{c}}$ & $63.11 \pm 16.26^{\mathrm{b}}$ & $204.36 \pm 46.71$ & $1.07 \pm 0.13^{\mathrm{b}}$ \\
Simvastatin & $891.71 \pm 348.21^{\mathrm{c}}$ & $60.95 \pm 16.84^{\mathrm{b}}$ & $184.01 \pm 37.53$ & $0.9 \pm 0.18^{\mathrm{b}}$ \\
\hline
\end{tabular}

a Compared with NC, $p<0.05 ;{ }^{\mathrm{b}}$ Compared with MC, $p<0.05 ;{ }^{\mathrm{c}}$ Compared with $\mathrm{CF}, p<0.05$.

\subsection{Lipid Metabolism Related Enzyme Activities in Livers}

As shown in Table 10, compared with the NC group, the liver levels of FAS, HMGCoAR, and DGAT in the MC group increased, while FA $\beta \mathrm{O}$, CYP7A1, and HL decreased significantly $(p<0.05)$. After the intervention of chrysanthemum flavonoids, luteolin, luteoloside, and simvastatin, the liver levels of FAS, HMG-CoA, and DGAT decreased significantly $(p<0.05)$, except for FAS in the luteoloside group. The liver levels of FA $\beta \mathrm{O}$, CYP7A1, and HL increased significantly $(p<0.05)$, except for HL in the luteoloside group. Compared with the CF group, the differences of all liver enzymes in the luteoloside group were statistically significant $(p<0.05)$. Other measures did not differ statistically between the three intervention groups and the simvastatin group. 
Table 10. Enzymes involved in fatty acid (FAS, FAßO), cholesterol (HMG-CoAR, CYP7A1), and triglycerides (DGAT, HL) metabolism in the liver.

\begin{tabular}{|c|c|c|c|c|c|c|}
\hline Group & $\begin{array}{c}\text { FAS } \\
(\mathrm{nmol} / \mathrm{g})\end{array}$ & $\begin{array}{l}\mathrm{Fa} \beta \mathrm{O} \\
(\mathrm{pg} / \mathrm{g})\end{array}$ & HMG-CoAR(ng/g) & $\begin{array}{c}\text { CYP7A1 } \\
\text { (ng/g) }\end{array}$ & DGAT(ng/g) & $\mathrm{HL}(\mu \mathrm{mol} / \mathrm{g})$ \\
\hline NC & $0.039 \pm 0.004$ & $12261.07 \pm 992.49$ & $55.11 \pm 2.83$ & $34.96 \pm 2.71$ & $15.55 \pm 1.89$ & $1.30 \pm 0.08$ \\
\hline MC & $0.055 \pm 0.005^{\mathrm{a}}$ & $8198.48 \pm 799.24^{a}$ & $76.43 \pm 4.25^{\mathrm{a}}$ & $23.40 \pm 1.59^{\mathrm{a}}$ & $25.26 \pm 1.90^{\mathrm{a}}$ & $1.03 \pm 0.07^{a}$ \\
\hline $\mathrm{CF}$ & $0.044 \pm 0.004^{\mathrm{a}, \mathrm{b}}$ & $11892.12 \pm 695.43^{\mathrm{b}}$ & $61.11 \pm 4.29^{\mathrm{a}, \mathrm{b}}$ & $32.18 \pm 1.47^{\mathrm{a}, \mathrm{b}}$ & $17.61 \pm 2.11^{\mathrm{a}, \mathrm{b}}$ & $1.21 \pm 0.06^{\mathrm{a}, \mathrm{b}}$ \\
\hline Luteolin & $0.048 \pm 0.005^{\mathrm{a}, \mathrm{b}}$ & $10500.34 \pm 904.70^{a, b, c}$ & $63.69 \pm 3.90^{\mathrm{a}, \mathrm{b}}$ & $30.57 \pm 2.66^{a, b}$ & $18.32 \pm 1.66^{\mathrm{a}, \mathrm{b}}$ & $1.23 \pm 0.07^{\mathrm{a}, \mathrm{b}}$ \\
\hline Luteoloside & $0.050 \pm 0.004^{\mathrm{a}, \mathrm{c}}$ & $9489.81 \pm 1118.32^{a, b, c}$ & $69.94 \pm 2.99^{a, b, c}$ & $26.55 \pm 2.87^{a, b, c}$ & $21.47 \pm 0.64^{a, b, c}$ & $1.03 \pm 0.09^{a, c}$ \\
\hline Simvastatin & $0.049 \pm 0.004^{\mathrm{a}, \mathrm{b}}$ & $9851.16 \pm 873.80^{a, b, c}$ & $71.02 \pm 5.25^{a, b, c}$ & $26.02 \pm 1.94^{\mathrm{a}, \mathrm{b}, \mathrm{c}}$ & $19.67 \pm 1.70^{a, b, c}$ & $1.19 \pm 0.07^{\mathrm{a}, \mathrm{b}}$ \\
\hline
\end{tabular}

\section{Discussion}

As a metabolic disease with abnormal blood lipid levels, hyperlipidemia is an important risk factor for many complications and increases the incidence and mortality of cardiovascular diseases [23,24]. Although western medicine is the main method of treating hyperlipidemia, their limitations such as adverse reactions and intolerance are often reported, including musculoskeletal pain, elevation of transaminase, and headaches. Therefore, the lipid-lowering effect and application of traditional Chinese herbal medicine have gradually become the focus of many scholars [24]. The known phytochemicals with lipid-lowering effects mainly include phytosterols, phenols, saponins, alkaloids, organic sulfides, and lectins [25]. Chrysanthemum is a common edible herb in China and has been reported to contain antibacterial, antiviral, anti-oxidant, and immunomodulatory effects [26]. Some studies have shown that the ethyl acetate fraction of chrysanthemum indicum (CIEA) might be beneficial for preventing obesity [27-29], and in vitro chrysanthemum morifolium flower extract inhibits adipogenesis of 3T3-L1 cells via AMPK/SIRT1 pathway activation [30]. Luteolin and quercetin specifically inhibited NPC1L1 to reduce high blood cholesterol levels [31]. In addition, luteolin can also induce the expression of ABCG-5/8 in the intestinal mucosa of mice, also increasing fecal cholesterol content. Therefore, it is speculated that luteolin can treat hypercholesterolemia mainly by inhibiting cholesterol synthesis [32]. Luteolin release depends on glucosidase activity and affects the ability of an artichoke extract to inhibit the biosynthesis of cholesterol [33]. Glucoside was observed to improve blood lipids through glycogen synthase kinase 3 in a rat model of type 2 diabetes [34].

The results revealed that the body weight gains of rats in the model groups were significantly higher than the NC group, and the weight gains in the Chrysanthemum flavonoids, Luteolin, and Luteoloside groups were lower than that in the MC group (Figure 1). Organ coefficients were significantly improved in the three intervention groups and the simvastatin group, and there was no significant difference among these groups (Table 4). CF, Luteolin, Luteoloside, and simvastatin significantly reduced the body fat and lipid levels of hyperlipidemia rats, and simvastatin had a better effect on the reduction of low-density lipoprotein, while the other indicators showed no significant difference (Table 5). These results suggest that there was no significant difference in anti-obesity and blood lipids between them.

The emergence of the hypothesis of lipid accumulation and overflow explains the damage of hyperlipidemia to the body [35]. Hyperlipidemia disrupts the lipid balance and leads to increased TG synthesis and deposition in the liver, which is considered to be the first attack of the fatty liver [36]. In this study, the liver index in the NC groups was significantly higher than in the model group, which means that there may be some pathological changes, although there are certain limitations [37]. Chrysanthemum flavonoids, Luteolin, and Luteoloside all significantly improved the degree of hepatic steatosis in hyperlipidemia rats (Figures 2 and 3). Studies have shown that the prolonged course of hyperlipidemia may be accompanied by different degrees of liver function damage, so the improvement of liver function also needs to be observed in the treatment of hyperlipidemia [38]. The three indexes of serum liver function in the model group were significantly increased, suggesting that the hyperlipidemia rats may be accompanied by a certain degree of liver damage (Table 7). Chrysanthemum flavonoids, Luteolin, Luteoloside, and simvastatin also had a 
protective effect on liver injury in the hyperlipidemia SD rats and there was no significant difference between them.

The "second strike theory" holds that the disorder of the antioxidant system further develops a fatty liver [39], which can be manifested as the increase in oxygen-free radical products and/or the decrease in the activity of free radical scavenging enzymes [40]. As antioxidant enzymes that remove reactive oxygen species in the body, SOD, GSH-Px, and CAT can reflect the antioxidant capacity of the body, together with the lipid peroxidation product MDA. The results showed that the antioxidant level in liver tissue decreased in hyperlipidemia SD rats. Chrysanthemum flavonoids, Luteolin, Luteoloside, and simvastatin can increase the activity of antioxidant enzymes and reduce lipid peroxidation products (Table 8). It is suggested that the effect of improving hepatic steatosis may be achieved by inhibiting lipid peroxidation and increasing the activity of antioxidant enzymes. However, the antioxidant activity of chrysanthemum flavonoids was better than that of the other three groups

The liver is an important player in regulating lipid metabolism. Imbalances of lipid metabolism in the liver can lead to non-physiological accumulation of triglycerides or steatosis [41,42]. Liver steatosis can be caused by complex processes: increased fatty acid uptake, synthesis of fat, and triglycerides combined with biogenesis or the growth of lipid droplets-LD catabolism decreased (including fatty acid oxidation) and the secretion of triglycerides or very-low-density lipoprotein (VLDL) was impaired [43]. Therefore, the activities of some lipid-metabolizing enzymes in the liver were detected from the aspects of synthesis and catabolism to explore the effects on liver lipid metabolism. Fatty acid synthase (FAS or FASN) plays a pivotal role in de novo lipogenesis, and functions as a central regulator of lipid metabolism [44,45]. Many FASN inhibitors have been successfully applied for the treatment of other diseases such as obesity, type 2 diabetes, and NAFLD [46]. FA $\beta O$ is a key enzyme in fatty acid catabolism, which promotes the $\beta$-oxidation of fatty acids to regulate lipid metabolism [47]. Increased activation and decreased $\beta$-oxidation of fatty acids may lead to liver lipidosis [48]. Fatty acid metabolism was improved in hyperlipidemia rats fed with Chrysanthemum flavonoids, Luteolin, Luteoloside, and simvastatin. Chrysanthemum flavonoids may improve the activity of fatty acid metabolic enzymes better than others. Cholesterol $7 \alpha$-hydroxylase (CYP7A1) is a rate-limiting enzyme that catalyzes the liver synthesis of bile acids, which converts cholesterol in non-hepatic peripheral tissues to bile acids [49]. The enzyme 3-hydroxy-3-methylglutaryl coenzyme A reductase (HMG-CoAR) is a rate-limiting enzyme of cholesterol synthesis, and its inhibitors are often used to treat hypercholesterolemia [50]. Chrysanthemum flavonoids, Luteolin, Luteoloside, and simvastatin can significantly improve the activity of cholesterol metabolism enzymes but Chrysanthemum flavonoids and luteolin may be better than the other two groups. Hepatic Lipase (HL) is an innate liver enzyme that promotes the clearance of TG from very-low-density lipoprotein (VLDL) pools, thereby regulating plasma TG content, but its release and transport are controlled by HDL [51]. Diacylglycerol acyltransferase (DGAT) is the final rate-limiting enzyme for the synthesis of triacylglycerol, mainly catalyzing the binding of diacylglycerol and fatty acids acyl. It is commonly used as a target for the treatment of obesity and diabetes [52]. The results showed that triglyceride metabolism was improved in hyperlipidemia rats fed with Chrysanthemum flavonoids, Luteolin, Luteoloside, and simvastatin. Chrysanthemum flavonoids and luteolin may be better than the other two groups.

\section{Conclusions}

In conclusion, Chrysanthemum flavonoids, Luteolin, and Luteoloside have antiobesity effects and improve the serum lipids and fatty liver. The mechanism of action is related to the regulation of antioxidant levels and enzyme activities related to lipid metabolism in the liver. However, chrysanthemum flavonoids had a better effect on improving the antioxidant level and lipid metabolism enzyme activity. As hyperlipemia is a chronic disease, the intervention in this study is short, so the long-term intervention effect 
of Chrysanthemum flavonoids may be better. Further studies on other compounds related to this effect and the mechanism of action from the expression of genes and key proteins are needed.

Author Contributions: Conceptualization, software, formal analysis and writing, J.S.; methodology and validation, Z.W.; supervision, L.C., G.S. All authors have read and agreed to the published version of the manuscript.

Funding: This research was funded by the National Key Research and Development Plan(2016YED0400604); Postgraduate Research \& Practice Innovation Program of Jiangsu Province(KYCX17_0190); and Scientific and Technological Research Projects of Chongqing Education Commission (KJQN201801232).

Institutional Review Board Statement: The study was conducted according to the guidelines of the Declaration of Helsinki, and approved by the Institutional Review Board of Southeast University (protocol code 2015ZDSYLL004.0).

Informed Consent Statement: Not applicable.

Data Availability Statement: The data presented in this study are available on request from the corresponding author. The data are not publicly available due to it involves some of the genetic data from our later mechanistic studies.

Conflicts of Interest: No potential conflict of interest was reported by the authors.

\section{References}

1. Lu, B.; Li, M.; Yin, R. Phytochemical Content, Health Benefits, and Toxicology of Common Edible Flowers: A Review (2000-2015). Crit. Rev. Food Sci. Nutr. 2016, 56 (Suppl. 1), S130-S148. [CrossRef]

2. Yuan, H.; Jiang, S.; Liu, Y.; Daniyal, M.; Jian, Y.; Peng, C.; Shen, J.; Liu, S.; Wang, W. The flower head of Chrysanthemum morifolium Ramat. (Juhua): A paradigm of flowers serving as Chinese dietary herbal medicine. J. Ethnopharmacol. 2020, 261, 113043. [CrossRef] [PubMed]

3. Shao, Y.; Sun, Y.; Li, D.; Chen, Y. Chrysanthemum indicum L.: A Comprehensive Review of its Botany, Phytochemistry and Pharmacology. Am. J. Chin. Med. 2020, 48, 871-897. [CrossRef] [PubMed]

4. Chang, X.; Wei, D.; Chen, D.; Chen, D.; Yan, H.; Sun, X.; Zhu, W.; Duan, J. Historical origin and development of medicinal and tea Chrysanthemum morifolium resources. Mod. Chin. Med. 2019, 21, 116-123, 145.

5. Yang, P.F.; Feng, Z.M.; Yang, Y.N.; Jiang, J.S.; Zhang, P.C. Neuroprotective Caffeoylquinic Acid Derivatives from the Flowers of Chrysanthemum morifolium. J. Nat. Prod. 2017, 80, 1028-1033. [CrossRef] [PubMed]

6. Yang, P.F.; Yang, Y.N.; He, C.Y.; Chen, Z.F.; Yuan, Q.S.; Zhao, S.C.; Fu, Y.F.; Zhang, P.C.; Mao, D.B. New Caffeoylquinic Acid Derivatives and Flavanone Glycoside from the Flowers of Chrysanthemum morifolium and Their Bioactivities. Molecules 2019, 24, 850. [CrossRef] [PubMed]

7. Li, S. Quality Assessment and Standard Invistigation of Chrysanthemum Morifolium; Bejing University of Chinese Medicine: Beijing, China, 2015.

8. Chinese Pharmacopoeia Commission. Pharmacopoeia of the People's Republic of China; Chemical Industry Press: Beijing, China, 2015.

9. Miao, M.; Yang, L.; Ying, R.; Sun, R.; Yin, J.; Qi, L.; Zuo, P.; Sun, G. Determination of total flavonoids and total steroids in 12 kinds of commercial edible flowers. Food Res. Dev. 2009, 30, 122-125.

10. Wang, F.; Miao, M.; Xia, H.; Yang, L.G.; Wang, S.K.; Sun, G.J. Antioxidant activities of aqueous extracts from 12 Chinese edible flowers in vitro and in vivo. Food Nutr. Res. 2017, 61, 1265324. [CrossRef]

11. Wang, S.; Li, Y. Experimental study on lowering blood lipid of total flavonoids in Chrysanthemum. Mod. Food 2017, 3, 123-125.

12. Wang, B.; Chen, W.; Sun, J.; Wang, W. Prevention and control effect of total flavonoids from Chrysanthemum sativum on alcoholic fatty liver disease in rats. J. Anhui Med. Univ. 2011, 46, 1022-1025.

13. Chen, C.; Qu, Y.; Zhu, X.; Shen, Y.P.; Hong, F. Study on the Effect of Extract of Chrysanthemum willow on Blood Lipid Regulation. J. Jilin Med. Coll. 2010, 31, 321-324.

14. Sun, J.; Wang, Z.; Wang, S.; Liu, H.C.; Fu, W.L.; Sun, G.J. Effect of total flavonoids from chrysanthemum on lowering blood lipid in hyperlipidemia rats. In Proceedings of the 13th National Conference on Nutrition and Health Food Science and the 7th Sino-Korean International Symposium on Phytonutrients, Wuxi, China, 14 September 2017.

15. Wang, T.; Wang, S.; Huang, G.; Song, Z.X.; Yang, L.G.; Sun, G.J. Determination of main active components in chrysanthemum and their antioxidant activity. Food science. 2013, 34, 95-99.

16. Yang, L.G.; Sun, G.; Fu, W.; Huang, N.; Wang, S. Separation and purification of flavonoids from Chrysanthemum by macroporous resin and identification. Food Ind. Technol. 2010, 31, 125-128. 
17. Wang, Z.; Xia, H.; Yang, X.; Song, Z.X.; Yang, L.G.; Sun, G.J. Optimization of ultrasonic extraction process of chrysanthemum flavone by response surface methodology. In Proceedings of the 13th National Nutrition Science Conference of Chinese Nutrition Society and Global Chinese Nutrition Scientists Conference, Beijing, China, 22 May 2017.

18. Wang, Z.; Sun, G.; Wang, S.; Yang, L.G. Determination of Luteolin -7-O- glucoside in Chrysanthemum by HPLC and MASS spectrometry. In Proceedings of the 13th National Nutrition and Health Food Science Conference \& 7th China-ROK International Symposium on Phytonutrients, Wuxi, China, 14 September 2017.

19. Sun, J.; Wang, Z.; Liu, H.; Fu, W.L.; Sun, G.J. Study on lowering blood lipid of hyperlipidemia rats by total flavonoids from Chrysanthemum. In Proceedings of the 13th National Nutrition and Health Food Science Conference \& 7th China-ROK International Symposium on Phytonutrients, Wuxi, China, 14 September 2017.

20. Liu, G.; Zhang, Y.; Liu, C.; Xu, D.Q.; Zhang, R.; Chen, Y.; Pan, Y.; Huang, C.; Chen, Y. Luteolin alleviates alcoholic liver disease induced by chronic and binge ethanol feeding in mice. J. Nutr. 2014, 144, 1009-1015. [CrossRef] [PubMed]

21. Antonisamy, P. Experimental study on gastroprotective efficacy and mechanisms of luteolin-7-O-glucoside isolated from Ophiorrhiza mungos Linn. in different experimental models. J. Funct. Foods 2016, 25, 302-313. [CrossRef]

22. Showande, S.A.-O.X.; Adegbolagun, O.M.; Igbinoba, S.I.; Fakeye, T.O. In vivo pharmacodynamic and pharmacokinetic interactions of Hibiscus sabdariffa calyces extracts with simvastatin. J. Clin. Pharm. Ther. 2017, 42, 695-703. [CrossRef] [PubMed]

23. Xiao, C.; Dash, S.; Morgantini, C.; Hegele, R.A.; Lewis, G.F. Pharmacological Targeting of the Atherogenic Dyslipidemia Complex: The Next Frontier in CVD Prevention Beyond Lowering LDL Cholesterol. Diabetes 2016, 65, 1767-1778. [CrossRef] [PubMed]

24. Karr, S. Epidemiology and management of hyperlipidemia. Am. J. Manag. Care 2017, 23, S139-S148. [PubMed]

25. Xue, Z.; Wang, R.; Yu, W.; Kou, X.H. Cholesterol-Lowering Mechanisms of Phytochemicals: A Review. Curr. Top. Nutraceutical Res. 2017, 15, 111-121.

26. Zheng, J.; Lu, B.; Xu, B. An update on the health benefits promoted by edible flowers and involved mechanisms. Food Chem. 2021, 340, 127940. [CrossRef]

27. Nepali, S.; Cha, J.Y.; Ki, H.H.; Lee, H.Y.; Kim, Y.H.; Kim, D.K.; Song, B.J.; Lee, Y.M. Chrysanthemum indicum Inhibits Adipogenesis and Activates the AMPK Pathway in High-Fat-Diet-Induced Obese Mice. Am. J. Chin. Med. 2018, 46, 119-136. [CrossRef]

28. Shon, J.C.; Kim, W.C.; Ryu, R.; Wu, Z.; Seo, J.S.; Choi, M.S.; Liu, K.H. Plasma Lipidomics Reveals Insights into Anti-Obesity Effect of Chrysanthemum morifolium Ramat Leaves and Its Constituent Luteolin in High-Fat Diet-Induced Dyslipidemic Mice. Nutrients 2020, 12, 2973. [CrossRef]

29. Ryu, R.; Kwon, E.Y.; Choi, J.Y.; Shon, J.C.; Liu, K.H.; Choi, M.S. Chrysanthemum Leaf Ethanol Extract Prevents Obesity and Metabolic Disease in Diet-Induced Obese Mice via Lipid Mobilization in White Adipose Tissue. Nutrients 2019, $11,1347$. [CrossRef]

30. Lee, M.S.; Kim, Y. Chrysanthemum morifolium Flower Extract Inhibits Adipogenesis of 3T3-L1 Cells via AMPK/SIRT1 Pathway Activation. Nutrients 2020, 12, 2726. [CrossRef]

31. Nekohashi, M.; Ogawa, M.; Ogihara, T.; Nakazawa, K.; Kato, H.; Misaka, T.; Abe, K.; Kobayashi, S. Luteolin and quercetin affect the cholesterol absorption mediated by epithelial cholesterol transporter niemann-pick c1-like 1 in caco-2 cells and rats. PLoS ONE 2014, 9, e97901. [CrossRef]

32. Wong, T.Y.; Tan, Y.Q.; Lin, S.M.; Leung, L.K. Apigenin and luteolin display differential hypocholesterolemic mechanisms in mice fed a high-fat diet. Biomed. Pharm. 2017, 96, 1000-1007. [CrossRef]

33. Gebhardt, R. Inhibition of cholesterol biosynthesis in HepG2 cells by artichoke extracts is reinforced by glucosidase pretreatment. Phytother. Res. 2002, 16, 368-372. [CrossRef] [PubMed]

34. Azevedo, M.F.; Camsari, C.; Sá, C.M.; Lima, C.F.; Fernandes-Ferreira, M.; Pereira-Wilson, C. Ursolic acid and luteolin-7-glucoside improve lipid profiles and increase liver glycogen content through glycogen synthase kinase-3. Phytother. Res. 2010, 24 (Suppl. 2), S220-S224. [CrossRef] [PubMed]

35. Unger, R.H. Minireview: Weapons of lean body mass destruction: The role of ectopic lipids in the metabolic syndrome. Endocrinology 2003, 144, 5159-5165. [CrossRef] [PubMed]

36. Friedman, J. Fat in all the wrong places. Nature 2002, 415, 268-269. [CrossRef] [PubMed]

37. Yuan, B. Significance and deficiency of organ coefficient in drug safety evaluation. Chin. J. New Drugs. 2003, 11, 960-963.

38. Lin, T.T.; Lin, C.H.; Chang, C.L.; Chi, C.H.; Chang, S.T.; Sheu, W.H. The effect of diabetes, hyperlipidemia, and statins on the development of rotator cuff disease: A nationwide, 11-year, longitudinal, population-based follow-up study. Am. J. Sports Med. 2015, 43, 2126-2132. [CrossRef] [PubMed]

39. Day, C.P.; James, O.F. Steatohepatitis: A tale of two "hits"? Gastroenterology 1998, 114, 842-845. [CrossRef]

40. Romanova, D.; Vachalkova, A.; Cipak, L.; Ovesna, Z.; Rauko, P. Study of antioxidant effect of apigenin, luteolin and quercetin by DNA protective method. Neoplasma 2001, 48, 104-107. [PubMed]

41. Wang, Y.; Ding, W.X.; Li, T. Cholesterol and bile acid-mediated regulation of autophagy in fatty liver diseases and atherosclerosis. Biochim. Biophys. Acta Mol. Cell Biol. Lipids 2018, 1863, 726-733. [CrossRef]

42. Zhou, H.; Liu, R. ER stress and hepatic lipid metabolism. Front. Genet. 2014, 5, 112. [CrossRef]

43. Gluchowski, N.L.; Becuwe, M.; Walther, T.C.; Farese, R.V. Lipid droplets and liver disease: From basic biology to clinical implications. Nat. Rev. Gastroenterol. Hepatol. 2017, 14, 343-355. [CrossRef]

44. Fhu, C.W.; Ali, A. Fatty Acid Synthase: An Emerging Target in Cancer. Molecules 2020, 25, 3935. [CrossRef] [PubMed] 
45. Angeles, T.S.; Hudkins, R.L. Recent advances in targeting the fatty acid biosynthetic pathway using fatty acid synthase inhibitors. Expert Opin. Drug Discov. 2016, 11, 1187-1199. [CrossRef] [PubMed]

46. Jiang, H.; Gan, T.; Zhang, J.; Ma, Q.; Liang, Y.; Zhao, Y. The Structures and Bioactivities of Fatty Acid Synthase Inhibitors. Curr. Med. Chem. 2019, 26, 7081-7101. [CrossRef]

47. Cherkaoui-Malki, M.; Surapureddi, S.; El-Hajj, H.I.; Vamecq, J.; Andreoletti, P. Hepatic steatosis and peroxisomal fatty acid beta-oxidation. Curr. Drug Metab. 2012, 13, 1412-1421. [CrossRef] [PubMed]

48. Li, P.; Li, X.B.; Fu, S.X.; Wu, C.C.; Wang, X.X.; Yu, G.J.; Long, M.; Wang, Z.; Liu, G.W. Alterations of fatty acid $\beta$-oxidation capability in the liver of ketotic cows. J. Dairy Sci. 2012, 95, 1759-1766. [CrossRef] [PubMed]

49. Ge, M.X.; Shao, R.G.; He, H.W. Advances in understanding the regulatory mechanism of cholesterol 7 $\alpha$-hydroxylase. Biochem. Pharm. 2019, 164, 152-164. [CrossRef] [PubMed]

50. Gesto, D.S.; Pereira CM, S.; Cerqueira, N.; Sousa, S.F. An Atomic-Level Perspective of HMG-CoA-Reductase: The Target Enzyme to Treat Hypercholesterolemia. Molecules 2020, 25, 3891. [CrossRef] [PubMed]

51. Chatterjee, C.; Sparks, D.L. Hepatic lipase, high density lipoproteins, and hypertriglyceridemia. Am. J. Pathol. 2011, 178, 1429-1433. [CrossRef]

52. Bhatt-Wessel, B.; Jordan, T.W.; Miller, J.H.; Peng, L. Role of DGAT enzymes in triacylglycerol metabolism. Arch. Biochem. Biophys. 2018, 655, 1-11. [CrossRef] 